\title{
AN OVERVIEW OF STANDARDS AND REGULATION CONCERNING EXPOSURE TO RADIOFREQUENCY FIELDS
}

\author{
Annamaria PALJANOS, \\ paljanosanna@yahoo.com \\ Călin MUNTEANU \\ calin.munteanu@et.utcluj.ro
}

TECHNICAL UNIVERSITY CLUJ NAPOCA, ROMANIA

\begin{abstract}
Technological development put international organisations to effort in order to issue and continuously reassess standards concerning electromagnetic radiation protection issues. Protection standards have to be continuously reviewed as new data become available. This article provides a brief overview of updates implemented by the latest available protection standards. Currently, standards do not incorporate appropriate safety factors for protection against long-term effects of exposure to electromagnetic fields, thus protection is provided only for the established short term effects of electromagnetic fields on the human body. However, there is still a great deal of questions related to differences in limitations set by international organisations that have issued recommendations for personnel protection against electromagnetic fields.
\end{abstract}

\section{Keywords}

Electromagnetic field exposure, basic restrictions, exposure limit values, reference levels, action levels

\section{Introduction}

Nowadays it is hard to find a form of technology that does not use some kind of electromagnetic energy. In the last century the level of environmental microwave radiation has increased by a factor of ten billion, thus protection of general public and moreover the occupationally exposed personnel became a necessary research direction.
European Council and Parliament have recently adopted Directive 2013/35/EU on the minimum health and safety requirements regarding the exposure of workers to the risks arising from physical agents (electromagnetic fields - EMF) [1]. The piece of legislation dealing with the exposure of the general population to EMF is the Council Recommendation 1999/519/EC, 
which set the exposure limits and also invites the Commission to keep the possible health effects of EMF under review.

While the protection of the population from potential health risks falls under Member States' responsibility, the Council Recommendation has established a set of Basic Restrictions and Reference Levels to provide harmonised guidance to the Member States and to create a basis for EU product safety legislation. These Basic Restrictions and Reference Levels are laid down by the International Commission on Non-Ionizing Radiation Protection (ICNIRP).

Romania, along with other Member States, would be required to follow the new directive. Previously, the issue of general public exposure to radiofrequency fields was covered by national legislation (Order 1193 from September 2006), as a delayed consequence of the Council Recommendation 1999/519/EC.

The Council Recommendation invites the Commission to keep the matters covered by this recommendation under review. In order to fulfil this obligation the European Commission periodically mandates the Scientific Committee on Emerging and Newly Identified Health Risks (SCENIHR) to assess whether the scientific evidence base would justify the revision of the reference levels recommended by the Council. SCENIHR has so far published four opinions on electromagnetic fields. The fourth opinion underwent public consultation in the first quarter of 2014 and was released in early January 2015. Briefly, the Committee reports that the results of current scientific research show that there are no evident adverse health effects if exposure remains below the levels recommended by the EU legislation [2].

Beside the EU Directive and Recommendation, other international organisations have issued regulations with respect to protection against adverse health effects caused by exposure to electromagnetic fields. Other non-member states also refer to ICNIRP guidelines for limiting exposure to time-varying electric, magnetic and electromagnetic fields (up to $300 \mathrm{GHz}$ ) [3] when setting limitations within national regulations. The present versions of IEEE (Institute of Electrical and Electronics Engineers) standard with respect to electromagnetic exposure is standard C95.12005, IEEE Standard for Safety Levels with Respect to Human Exposure to Radio Frequency Electromagnetic Fields, $3 \mathrm{kHz}$ to $300 \mathrm{GHz}$ [4].

First attempt to initiate a standard concerning personnel protection against possible effects of electromagnetic fields began in 1960 under the co-sponsorship of the US Department of the Navy and the IEEE. International standardization in the military is possible through the NATO Standardization Agency, an organization that has issued a great deal of standards adopted and implemented by member states. Standard Agreement (STANAG) 2345 Edition 3, "Evaluation and Control of Personnel Exposure to Radio Frequency Fields - $3 \mathrm{kHz}$ to $300 \mathrm{GHz}$ ", was last promulgated in February 2003 and should have been reassessed by 2006 . However, the review of STANAG 2345 was delayed due to the publication, by the European Commission (EC) on Worker Safety, of "Proposed Directive of the European Parliament and of the Council on the minimum health and safety requirements regarding the exposure of workers to the risks arising from physical agents (electromagnetic fields) (XXth individual Directive within the meaning of Article 16(1) of Directive 89/391/EEC)" which was promulgated only in June 2013. Specialist from the military (NATO Standardisation Agency) worked together with scientist from Institute of Electrical and Electronics Engineers standards association and released IEEE Standard for Military Workplaces Force Health Protection Regarding Personnel Exposure to Electric, Magnetic, and Electromagnetic Fields, $0 \mathrm{~Hz}$ to $300 \mathrm{GHz}$ [5].

Even if some differences can be found in classification of the environments rather than of the exposed personnel, threshold values, used terminology or averaging 
procedure these standards show close similarities, and are based on the same approach and rationale as ICNIRP guidelines. A common, basic feature is that all the above standards are firmly based on established science, and aim at protecting against all - and only - the adverse effects that have been well proven by qualified scientific research.

\section{General Public or Occupationally Exposed Population}

The occupationally exposed population consists of adults who are generally exposed under known conditions and are trained to be aware of potential risk and to take appropriate precautions. By contrast, the general public comprises individuals of all ages and of varying health status, and may include particularly susceptible groups or individuals [3]. General public is also used within the EU Recommendation and the IEEE standard. However, IEEE standard replaces the occupationally exposed with a group based on environment classification (persons in controlled environments).

The general public includes, but is not limited to, children, pregnant women, persons equipped with electronic medical devices, and persons using medications that may result in poor thermoregulatory system performance. Usually, individual members of the public may not be aware of their exposure or cannot take measures to limit exposure to electromagnetic fields. Under these circumstances more stringent limitations are provided for the general public than for the occupationally exposed.

Occupationally exposed personnel should benefit of proper training regarding electromagnetic exposure effects on the human body. They may also wear protection equipment and personal monitors in order to exclude overexposure scenarios.

The military workplace protection standards divide the environment in unrestricted (Zone 0) which apply to the general public and uninformed military personnel, and three restricted environments (Zone 1,2 and 3) based on level of electromagnetic training and protection equipment.

Regardless of the standard, when assessing exposure one should first analyse if it involves general public or occupationally exposed personnel and then apply corresponding limitations. Exposure may be under or supra evaluated if limitations are not properly chosen among general public and occupationally exposed.

\section{Basic Restrictions}

ICNIRP defines basic restrictions as "restrictions on the effects of exposure that are based on established health effects and are termed basic restrictions" [3]. Depending on frequency, the physical quantities used to specify the basic restrictions on exposure to EMF are current density, SAR, and power density.

The newly issued EU Directive replaces the term by "exposure limit values" which are values established on the basis of biophysical and biological considerations, in particular on the basis of scientifically wellestablished short-term and acute direct effects, i.e. thermal effects and electrical stimulation of tissues [1]. However IEEE uses both basic restrictions [5] and dosimetric reference limits [6] to express the same physical quantities.

In the $1 \mathrm{~Hz}-10 \mathrm{MHz}$ frequency band basic restrictions are expressed in terms of current densities. Specific absorption rate is used to provide basic restriction in the $100 \mathrm{kHz}-$ $10 \mathrm{GHz}$ frequency range, and above $10 \mathrm{GHz}$ they are expressed in terms of power density. Specific absorption rate (SAR) is a measure of the rate at which energy is absorbed by the human body when exposed to a radio frequency electromagnetic field, and is the most common physical quantity used to assess human exposure to electromagnetic fields. The table below provides SAR restrictions for general public and occupational exposure 
Basic SAR restrictions in different protection standards

\begin{tabular}{|c|c|c|c|c|c|}
\hline $\begin{array}{l}\text { Frequency } \\
\text { range }\end{array}$ & \multicolumn{2}{|c|}{ Standard } & $\begin{array}{c}\text { SAR } \\
\text { (W/Kg) } \\
\text { Whole body } \\
\text { exposure }\end{array}$ & $\begin{array}{c}\text { SAR } \\
(\mathrm{W} / \mathrm{Kg}) \\
\text { Head } \\
\text { and trunk } \\
\end{array}$ & $\begin{array}{c}\text { SAR } \\
\text { (W/Kg) } \\
\text { Limbs }\end{array}$ \\
\hline \multirow{2}{*}{$\begin{array}{c}100 \mathrm{KHz}- \\
3 \mathrm{GHz}\end{array}$} & $\begin{array}{l}\text { General } \\
\text { Public }\end{array}$ & $\begin{array}{l}\text { IEEE, ICNIRP, } \\
\text { IEEE-2345, EU }\end{array}$ & 0.08 & $2^{*}$ & $4^{*}$ \\
\hline & $\begin{array}{c}\text { Occupational } \\
\text { exposure }\end{array}$ & $\begin{array}{l}\text { IEEE, ICNIRP, } \\
\text { IEEE-2345, EU }\end{array}$ & 0.4 & $10^{*}$ & $20^{*}$ \\
\hline
\end{tabular}

*Averaged over $10 \mathrm{~g}$ of tissue

Exposure time (T)-6 minutes

Some protection standards provide SAR restrictions up to $10 \mathrm{GHz}$ (ICNIRP, EU recommendation), while other express basic restrictions above $3 \mathrm{GHz} / 6 \mathrm{GHz}$ frequencies in terms of power density (IEEE, EU). Whole body SAR values were calculated based on the established biological and health effects that were consistent with responses to a body temperature rise of more than $1^{\circ} \mathrm{C}$. This level of temperature increase results from exposure of individuals under moderate environmental conditions to a whole-body SAR of approximately $4 \mathrm{~W} / \mathrm{kg}$ for about $30 \mathrm{~min}$. A whole-body average SAR of $0.4 \mathrm{~W} / \mathrm{kg}$ has therefore been chosen as the restriction that provides adequate protection for occupational exposure. An additional safety factor of 5 is introduced for exposure of the public, giving an average whole-body SAR limit of $0.08 \mathrm{~W} / \mathrm{kg}$.

In the same frequency range the peak local SAR for any $1 \mathrm{~g}$ of tissue (defined as a tissue volume in the shape of a cube) should not exceed 8 and1.6 W/kg for the head and trunk regions for controlled and uncontrolled environments, respectively. A noticeable difference between the widely used IEEE and ICNIRP standards is that peak SARs are to be calculated over $1 \mathrm{~g}$ of tissue for the IEEE standards, while ICNIRP suggested a considerably larger mass of tissue $(10 \mathrm{~g})$ for the head and trunk.

However, if exposure is localised for parts of the body (head, trunk, limbs), SAR value is averaged over $10 \mathrm{~g}$ of tissue. The previous NATO 2345 protection standard used SAR values averaged over $1 \mathrm{~g}$ of tissue, but after the latest review it modified the mass to $10 \mathrm{~g}$, also used by IEEE and ICNIRP.

\section{Reference Levels}

Because assessing compliance with basic restrictions is difficult, protection standards have set reference levels in terms of external measurable field parameters or contact and induced currents. Reference levels are derived from the basic restrictions, considering the appropriate safety factors for plane wave condition (far field). The term is used within ICNIRP standard. IEEE uses "reference levels", "maximum permissible exposure" [5] or "exposure reference level" [6] to express the highest level of an electric field, magnetic field, electromagnetic field, induced current or contact current, or voltage to which the standard permits exposure, and which provides an adequate margin of safety against established adverse health effects.

Even thaw ICNIRP standard was transposed into EU legislation, EU Directive [1] changed the term to "action level" to express operational levels established for the purpose of simplifying the process of demonstrating the compliance with relevant exposure limit values.

Reference level values are intended to be spatially averaged over the entire area of the human body and correspond to calculated or measured field values at the workplace in the absence of the worker. As expected, different reference levels are set for whole 
body exposure compared to localised exposure condition.

For radiofrequency fields reference levels are set in terms of external electric field strength, magnetic fields strength and power density. EU Directive uses magnetic flux density instead of magnetic field strength. Reference levels for the $3-300 \mathrm{MHz}$ frequency band can be seen in Table no. 2 .
Some noticeable differences appear in the $3-10 \mathrm{MHz}$ frequency range. For both electric and magnetic field strength ICNIRP reference levels are stricter than those issued by IEEE. If we consider that reference levels are derived from basic restrictions, which are the same for ICNIRP and IEEE, an open question arises.

Reference levels in different protection standards

Table no. 2

\begin{tabular}{|c|c|c|c|c|}
\hline \multicolumn{2}{|c|}{ Frequency range (MHz) } & $3-10$ & $10-100$ & 100-300 \\
\hline \multirow{8}{*}{$\begin{array}{c}\text { Electric } \\
\text { field } \\
\text { strength } \\
(\mathrm{V} / \mathrm{m})\end{array}$} & $\begin{array}{l}\text { IEEE - } 2345 \\
\text { Zone } 0\end{array}$ & $823.8 / \mathrm{f}$ & 27.5 & 27.5 \\
\hline & $\begin{array}{c}\text { IEEE - } 2345 \\
\text { Zone } 1 \\
\end{array}$ & $1842 / \mathrm{f}$ & 61.4 & 61.4 \\
\hline & IEEE - General public & $823.8 / \mathrm{f}$ & 27.5 & 27.5 \\
\hline & IEEE Controlled environment & $1842 / \mathrm{f}$ & 61.4 & 61.4 \\
\hline & $\begin{array}{c}\text { ICNIRP } \\
\text { General public }\end{array}$ & $87 / \sqrt{6}$ & 28 & 28 \\
\hline & $\begin{array}{c}\text { ICNIRP } \\
\text { Occupational exposure }\end{array}$ & $610 / f$ & 61 & 61 \\
\hline & EU Recommendation & $87 / \sqrt{f 1}$ & 28 & 28 \\
\hline & EU Directive & 610 & 61 & 61 \\
\hline \multirow{7}{*}{$\begin{array}{l}\text { Magnetic } \\
\text { field } \\
\text { strength } \\
(\mathrm{A} / \mathbf{m})\end{array}$} & $\begin{array}{l}\text { IEEE - } 2345 \\
\text { Zone } 0\end{array}$ & $16.3 / f$ & 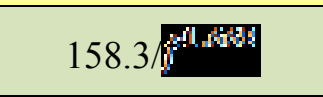 & 0.0729 \\
\hline & $\begin{array}{l}\text { IEEE - } 2345 \\
\text { Zone } 1 \\
\end{array}$ & $16.3 / f$ & $16.3 / \mathrm{f}$ & 0.163 \\
\hline & IEEE - General public & $16.3 / f$ & $158.3 / 8$ & 0.0729 \\
\hline & IEEE Controlled environment & $16.3 / \mathrm{f}$ & $16.3 / \mathrm{f}$ & 0.163 \\
\hline & $\begin{array}{c}\text { ICNIRP } \\
\text { General public } \\
\end{array}$ & $0.73 / \mathrm{f}$ & 0.073 & 0.073 \\
\hline & $\begin{array}{c}\text { ICNIRP } \\
\text { Occupational exposure } \\
\end{array}$ & $1.6 / \mathrm{f}$ & 0.16 & 0.16 \\
\hline & EU Recommendation & $0.73 / \mathrm{f}$ & 0.073 & 0.073 \\
\hline \multirow{8}{*}{$\begin{array}{l}\text { Power } \\
\text { density } \\
\left(\mathrm{W} / \mathrm{s}^{2} \mathrm{~d}^{2}\right)\end{array}$} & $\begin{array}{c}\text { IEEE - } 2345 \\
\text { Zone } 0 \\
\end{array}$ & 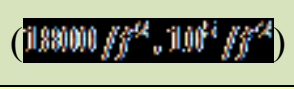 & 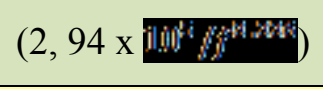 & 2 \\
\hline & $\begin{array}{c}\text { IEEE - } 2345 \\
\text { Zone } 1 \\
\end{array}$ & 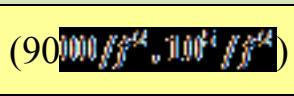 & 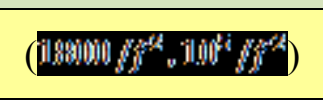 & 10 \\
\hline & IEEE - General public & 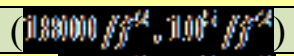 & 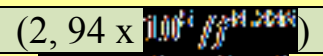 & 2 \\
\hline & IEEE Controlled environment & 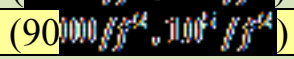 & 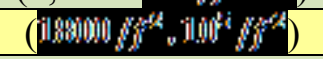 & 10 \\
\hline & $\begin{array}{c}\text { ICNIRP } \\
\text { General public }\end{array}$ & - & 2 & 2 \\
\hline & $\begin{array}{c}\text { ICNIRP } \\
\text { Occupational exposure } \\
\end{array}$ & - & 10 & 10 \\
\hline & EU Recommendation & - & 2 & 2 \\
\hline & EU Directive & - & 50 & 50 \\
\hline
\end{tabular}




\section{Conclusions}

We have presented a brief overview of the most widely used standards concerning protection against health effects due to exposure to radiofrequency fields. ICNIRP standard, which was also implemented by European legislation, was adopted by most European countries while IEEE standard is in use in USA and Canada, slightly modified. After a series of reviews the present form of the standards are much more harmonized. There are still some open questions remaining on the differences in limits set by the two organizations.

There are countries that have issued their own laws concerning population protection against exposure to electromagnetic fields, most of which impose stricter limitations (Belgium or Russia).

Romania has implemented both European regulations concerning general population and occupational exposure protection standards. Special consideration was accorded to the military; the old version of the NATO 2345 protection standard was never promulgated as a standard within the Romanian Army. However, as a NATO member state we expect that the Romanian Army will implement as soon as possible the IEEE Standard for Military Workplaces regarding personnel exposure to electromagnetic fields.

We have to consider that these limitations are set based on the established health effects of the radiofrequency fields. Basic restrictions in the radiofrequency range mainly refer to SAR value, a physical quantity defined to protect against tissue damage by temperature elevation. Temperature elevation is one of the short term effects of exposure to radiofrequency fields. We have to consider the complexity of the human body and the fact that interaction mechanism on a long term exposure scale are not yet well understood, thus an open question remains on the relevance of the exposure metrics.

Acknoledgement

This paper was supported by the Human Resources Development Programme POSDRU/159/1.5/S/137516 financed by the European Social Fund and by the Romanian Government.

\section{References}

1. Directive 2013/35/EU of the European Parliament and of the council of 26 June 2013 on the minimum health and safety requirements regarding the exposure of workers to the risks arising from physical agents (electromagnetic fields) (20th individual Directive within the meaning of Article 16(1) of Directive 89/391/EEC), online at: http://eurlex.europa.eu/LexUriServ/LexUriServ.do?uri=OJ:L:2013:179:0001:0021:en:PDF

2. EC Recommendation, 1999, Council of the European Union Recommendation of 12 July 1999 on the limitation of exposure of the general public to electromagnetic fields $(0 \mathrm{~Hz}$ to $300 \mathrm{GHz}$ ), 1999/519/EC, Official Journal of the European Communities, L 199/59.

3. Scientific Committee on Emerging and Newly Identified Health Risks - SCENIHR Opinion on Potential health effects of exposure to electromagnetic fields (EMF), on line at http://ec.europa.eu/health/scientific committees/emerging/docs/scenihr o 041.pdf (accesed May, 2015)

4. ICNIRP Guidelines for limiting exposure to time-varying electric, magnetic and electromagnetic fields up to $300 \mathrm{GHz}$, published in Health Physics 74 (4), 1998: 494-522.

5. IEEE Std C95.1TM-2005, IEEE Standard for Safety Levels with Respect to Human Exposure to Radio Frequency Electromagnetic Fields, $3 \mathrm{kHz}$ to $300 \mathrm{GHz}$

6. IEEE, 2014, C95.1-2345-2014 - IEEE Standard for Military Workplaces-Force Health Protection Regarding Personnel Exposure to Electric, Magnetic, and Electromagnetic Fields, $0 \mathrm{~Hz}$ to $300 \mathrm{GHz}$. 